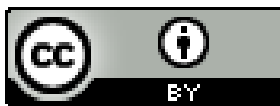

\title{
INVISIBILIDADE DO PROTAGONISMO NEGRO FEMININO E O DESIGN DE GAMES: MERCADO, DESENVOLVIMENTO E PRODUÇÃO
}

\author{
Eudaldo Francisco dos Santos Filho ${ }^{1}$ \\ Universidade do Estado da Bahia - UNEB, Departamento de Ciências Exatas e da \\ Terra, Salvador, BA, Brasil. \\ Beatriz Ramos da Silva ${ }^{2}$ \\ Universidade do Estado da Bahia - UNEB, Departamento de Ciências Exatas e da \\ Terra, Salvador, BA, Brasil.
}

Resumo: O presente artigo trata sobre os fatores mercadológicos, sociais e de produção que interferem na baixa representação da mulher negra na indústria de jogos digitais. Tal problemática é abordada com estudos como o de Davis (2016) e Djamila Ribeiro (2019), que confirmam como o racismo e sexismo afetam negativamente a presença das mulheres negras em diferentes ambientes e mídias. Tal fenômeno ocorre principalmente na mídia dos jogos, causando invisibilidade. Além disso, é feita uma abordagem dentro do campo do design com autores como Buchanan (2001) e Rogers (2014) para entender o contexto do desenvolvimento de jogos digitais.

Palavras-Chave: Protagonismo Negro Feminino; Jogos Digitais; Design de Personagem; Design de Jogos.

\section{INVISIBILITY OF BLACK FEMALE PROTAGONISM AND GAMES DESIGN: MARKET, DEVELOPMENT AND PRODUCTION}

\footnotetext{
${ }^{1}$ Graduação em Desenho Industrial pela Universidade do Estado da Bahia; Especialização em Administração Pública com Aprofundamento em Gestão pela Universidade Estadual de Feira de Santana e Especialização em Design de Produto pela UNEB; Mestrado em Desenho, Cultura e Contemporaneidade pela Universidade Estadual de Feira de Santana e Doutorado em Difusão do Conhecimento pela Universidade Federal da Bahia. Professor do Curso de Design UNEB. Compõe o corpo docente do Doutorado em Difusão do Conhecimento UNEB/UFBA/IFBA; Mestrado Profissional em Segurança Pública UGFBA e Programa de Pós-Graduação em Artes Visuais da UFBA. Perito Técnico do Departamento de Polícia Técnica especialista em Representação Facial Humana; Coordenador do LBI Laboratório de Biometria e Imagem UNEB. E-mail: eudaldofilho@gmail.com ; ORCID: https://orcid.org/0000-0002-5904-3262

${ }^{2}$ Graduação em Design (UNEB); Pós-graduanda em Gamificação, Engajamento e Marketing Digital na PUCPR Digital. E-mail: soubeatrizramos@ gmail.com ; ORCID: https://orcid.org/0000-0003-1776-0383
} 
Abstract: This paper deals with the marketing, social and production factors that interfere in the low representation of black women in the digital games industry. This problem is addressed with studies such as that of Davis (2016) and Djamila Ribeiro (2019), which confirm how racism and sexism negatively affects the presence of black women in different environments and media. Such phenomenon occurs mainly in the media of games, causing invisibility. In addition, an approach within the field of design is made with authors such as Buchanan (2001) and Rogers (2014) to understand the context of the development of digital games.

Keywords: Black Female Protagonism; Video Games; Character Design; Game Design.

\section{INVISIBILIDAD DEL PROTAGONISMO FEMENINO NEGRO Y DISEÑO DE JUEGOS: MERCADO, DESARROLLO Y PRODUCCIÓN}

Resumen: Este artículo trata sobre los factores de marketing, sociales y de producción que interfieren en la baja representación de las mujeres negras en la industria de los juegos digitales. Este problema se aborda con estudios como el de Davis (2016) y Djamila Ribeiro (2019), que confirman cómo el racismo y el sexismo inciden negativamente en la presencia de mujeres negras en diferentes entornos y medios. Tal fenómeno ocurre principalmente en los medios de los juegos, provocando invisibilidad. Además, se realiza una aproximación dentro del campo del diseño con autores como Buchanan (2001) y Rogers (2014) para comprender el contexto del desarrollo de los juegos digitales.

Palabras-clave: Protagonismo Femenino Negro; Juegos Digitales; Diseño de Personaje; Diseño de Juego.

\section{INVISIBILITÉ DU PROTAGONISME FÉMININ NOIRE ET LE DESIGN DU JEU: MARCHÉ, DÉVELOPPEMENT ET PRODUCTION}

Résumé: Cet article traite des facteurs marketing, sociaux et de production qui interferent avec la faible représentation des femmes noires dans l'industrie des jeux numériques. Ce problème est abordé par des études comme celle de Davis (2016) et Djamila Ribeiro (2019), qui confirment comment le racisme et le sexisme affectent négativement la présence des femmes noires dans différents environnements et médias. Un tel phénomène se produit principalement dans les médias des jeux, provoquant l'invisibilité. De plus, une approche dans le domaine du design est faite avec des auteurs comme Buchanan (2001) et Rogers (2014) pour comprendre le contexte du développement des jeux numériques.

Mots-clés: Protagonisme Féminin Noir; Jeux Numériques; Conception de Personnages; Le Design du Jeu.

\section{INTRODUÇÃO}

A construção da civilização, historicamente nos oferece uma miríade de elementos para afirmarmos que é uma prática corriqueira, a de elaboração de versões da realidade, como narrativas de fatos que acabam por se constituir em um reflexo de seu 
povo, seu ideário, valores, crenças, sua literatura, formal ou não formal, onde residem seus mais profundos arquétipos. A natural construção do conhecimento por meio de seus contos, estórias e personagens impactam sempre na difusão de valores constitutivos de um povo. E tal elemento nos leva a concluir que a idealização de narrativas e formulação de ícones predominam sempre perspectivas, e está eivada de fatos e construções em que a expressão social, política e afirmações das manifestações artística e cultural são representações das relações internas de poder de um povo e seus atores políticos sociais. Diante disso, a proposta deste trabalho visa identificar o protagonismo negro feminino dentro da indústria de games e como fenômenos contemporâneos podem comprovar este percurso.

A pesquisa foi uma revisão bibliográfica. A estrutura apresenta autores como Donovan (2010) e Rogers (2014), que auxiliam na definição do que é um jogo digital e uma breve história desta mídia. Com o assunto incorporado na perspectiva do design, o trabalho segue a abordagem da interferência de acontecimentos históricos e criação de discriminações que surgem como problemas na inserção da mulher no mercado de trabalho nos jogos digitais atualmente. Tais conteúdos são baseados em estudos de Davis (2016) e Ribeiro (2019), que abordam o racismo e sexismo na sociedade. Após isso, é apontada a abordagem da mulher negra como personagem em videogames e sua baixa predominância principalmente como protagonista em uma narrativa. Na última parte é comentado sobre como a desigualdade de classe influencia o público gamer e, por fim, as conclusões a respeito de todo o tema.

\section{PERCURSO HISTÓRICO DOS JOGOS DIGITAIS E O PROCESSO DE DESIGN}

Os jogos digitais têm se destacado como atividade central no campo do entretenimento moderno, mobilizando massas de consumidores ao redor do planeta, e, por outro lado, se estabelece como atividade trivial na vida de uma parcela cada vez mais numerosa da população. É também objeto de observação e pesquisa acadêmica.

Para Rogers (2014), um jogo pode ser definido como uma atividade que precisa ao menos de um jogador, regras e uma condição de vitória, e os videogames guardam estas características, mas se utilizando como meio uma tela de vídeo e maquinário dos quais são geradas as situações de jogo. Para o autor, a relação estabelecida entre o jogador 
x jogo dentro do videogame existe uma associação de artefatos tecnológicos que elevam o patamar da interação, incrementando as percepções, impressões e desafios à narrativa elaborada pelo jogo, fazendo com que a sensação de realidade paralela seja cada vez mais intensa. Mesmo que no início da era dos jogos virtuais apenas rudimentos de interatividade eram possíveis, como a trajetória de um ponto na tela que simulava o movimento de uma bolinha de tênis ou o movimento lateral de um carro numa pista de corrida, hoje essas relações de movimentos, controle e interações com o jogador são muito mais imersivas.

Estas sensações se fazem cada vez mais presentes por meio de artifícios tecnológicos, os periféricos, que manipulam e interagem com o ambiente virtual criado, fazendo com que a realidade virtual seja cada vez mais intensa e elaborada.

Segundo Rogers (2014), a origem dos primeiros jogos digitais é considerada a partir de estudos feitos após a Segunda Guerra Mundial, por estudantes da área de engenharia, física, matemática de universidades como o MIT (Massachusetts Institute of Technology) paralelamente com militares e funcionários do Brookhaven National Laboratories, situados nos Estados Unidos. Neste período, os jogos eram apenas testes de inteligência artificial com gráficos e mecânicas básicas, como por exemplo, o simulador de jogo da velha nomeado de $O X O$, feito em 1952. Além de serem exibidos em preto e branco eram transmitidos nas telas de osciloscópios. De acordo com Kent (2010), Tennis for Two foi um dos primeiros jogos a existir. Criado em 1958, era um tênis de mesa interativo para ser jogado em um osciloscópio. No entanto, a ideia de comercializar jogos foi feita apenas com o jogo Spacewar!

Figura 1: Jogo Spacewar! no microcomputador PDP-1. 


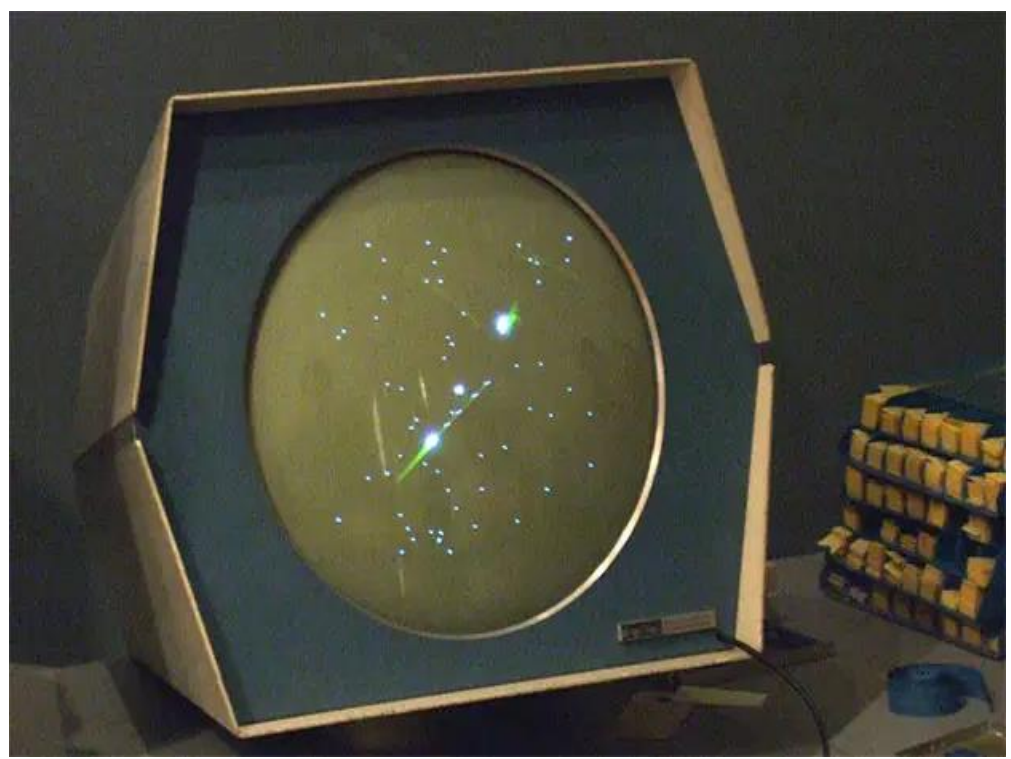

Fonte: https://super.abril.com.br/tecnologia/os-30-games-mais-importantes-de-todos-os-tempos/

Produzido pelo estudante do MIT, Steve Russel em 1961, foi o primeiro jogo feito em microcomputadores, como apresentado na figura 1.

Neste período, empresas de países, como Estados Unidos e Japão, começaram abrir espaço e investir no recente mercado e foram expandindo em paralelo aos avanços da tecnologia. Com a baixa disponibilização de computadores na época e como forma de disseminar o novo entretenimento, foram criados dispositivos portáteis e aparelhos para serem usados em conjunto com a televisão. Estes aparelhos foram favorecidos devido ao crescimento da produção e venda de televisores. "No final da década de 1950, quase 90\% das famílias norte-americanas tinham televisão em casa" (DONOVAN, 2010, n.p). Em 1968, Ralph Baer patenteou seu primeiro console doméstico, o Magnavox Odyssey e se tornou o pioneiro na história dos videogames. O console é conhecido como "um microprocessador que funciona como um dispositivo eletrônico que envia um sinal de vídeo para o aparelho de TV ou monitor do usuário" (ROGERS, 2014, p. 8, tradução nossa). Foi um aspecto que sucedeu em um grande salto para a popularização da indústria dos games.

Outro tipo de plataforma em que foi utilizado para acoplar os videogames foram as máquinas de jogos operados a moedas conhecidas como caça níqueis. Estas máquinas começaram a ser usadas para os videogames em forma de aluguel nos salões de jogos e passaram a ser denominadas como fliperamas ou arcade, chegando ao seu ápice na década de 1980. Nesta fase surgiram três modelos de fliperama: os uprights, cabines, as quais o jogador se mantinha em pé durante o jogo, tinha um monitor para visualizar e um 
painel com botões para a interação. Os cocktail tables, jogos de arcade, tinham uma mesa no topo que permitia o jogador ficar sentado e cockpits, cabines maiores que envolviam o jogador, com uma aparência que visava simular o tema do jogo, eram elaboradas também para sentar ou se inclinar com o objetivo de ter mais imersão.

Os jogos de arcade demandavam espaço e era dispendioso. Segundo Rogers (2014), os sistemas domésticos começaram a tomar o lugar de forma mais lucrativa, por consequência o comércio de fliperama foi à falência. Os computadores pessoais ou PCs, personal computer, começaram a se tornar mais populares no final da década de 1970 e tinham a possibilidade de emular os jogos de arcade. Assim sendo, o uso dos computadores possibilitou aos desenvolvedores criarem seus próprios jogos em casa. Por consequência, a disposição de um teclado, mouse e dispositivos de armazenagem possibilitaram a evolução de jogos mais complexos e estratégicos. Em meados da década de 1990, houve a popularização do gênero de jogo FPS ou first person shooter, que são jogos de tiro em primeira pessoa e os games que poderiam ser jogados online com outras pessoas com o uso da internet, os MMOs, Massively Multiplayer Online Game.

Logo alcançamos a fase em que os videogames começaram a fazer parte efetiva das vidas das pessoas, gerando discussões sobre a influência na vida e no comportamento dos jogadores. O número de horas destinadas a tal entretenimento se mostrava crescente e central, fazendo com que questões culturais, de saúde e comportamentais fossem levantadas.

Assim, não foram poucas as referências em que os jogos de luta e arte marcial como Street Fighter e Mortal Kombat lançados no final da década de 1980 e início de 1990, respectivamente, foram considerados inapropriados para menores de idade. Dessa forma, a popularidade de jogos eletrônicos no mercado nesse estilo chamou atenção de senadores dos Estados Unidos como Joseph Lieberman sobre a classificação indicativa dos conteúdos e este assunto foi levado à justiça. O professor do Departamento de Ensino e Aprendizagem da Universidade de Miami participou das audiências com seus estudos sobre o impacto dos videogames nas crianças. Em sua pesquisa presente no livro Video Kids: Making Sense of Nintendo, Provenzo define o videogame como "extremamente violentos, sexista e racista" (KENT, 2010, n.p, tradução nossa).

Kent (2010) descreveu a participação de Marilyn Droz, vice-presidente da National Coalition on Television Violence na audiência como testemunha. Ela declarou 
que a indústria de videogame fez o mesmo que a indústria de cinema, que confundem o desejo das crianças de ter ação com violência. Além disso, descreveu sobre a falta de presença feminina e a sensação dos videogames se transformarem em algo somente pensado para o público masculino.

Nossa pesquisa avança precisamente sobre o conteúdo e forma dos games. Constatamos que uma das questões centrais na indústria de entretenimento eletrônico em relação à construção dos jogos está relacionada à questão racial e de gênero. Percebemos que nos games modernos e mais imersivos e com o nível de realidade avançados, o protagonismo dos personagens não é inclusivo, exclui sistematicamente o negro e a mulher.

A partir do momento em que o jogo digital virou um produto do mercado, começaram a ser criadas profissões na área para desenvolvê-los. Conforme Rogers (2014), os primeiros videogames foram produzidos apenas por uma pessoa, com o tempo foram integradas profissões mais específicas, pois o desenvolvimento se tornou cada vez mais complexo, podendo ser comparado a times de produção audiovisual. Para Shell (2008), o design é um campo que participa de variadas maneiras na construção de um jogo digital. Ele serve de meio para entender principalmente a experiência humana, interligando-se com a psicologia e a antropologia. Este autor externa que o design raramente publica artigos para propagar o conhecimento adquirido. Corrobora com este mesmo pensamento Buchanan (2001), o qual afirma sobre o fato da existência de uma quebra entre a fase antiga e a mais moderna de pesquisas, as quais por muito tempo o design foi ligado à arquitetura e belas artes. $\mathrm{O}$ design contemporaneamente tem uma participação decisiva na produção e técnica da indústria dos games, mas ainda sem uma sistematização e participações acadêmicas relevantes, e com isso várias discussões em relação a sua gênese, arcabouço e posicionamentos são igualmente pouco reverberados e abordados com clareza.

\section{MULHER NEGRA NO MERCADO DE TRABALHO DOS JOGOS DIGITAIS}

Para entender o espaço da mulher negra atualmente, foi resgatado o histórico desde o período da escravidão, bem como o enfrentamento contra o racismo. Em referência à mulher negra no período da escravatura era considerada uma propriedade utilizada para o trabalho e desprovida de feminilidade. Além de serem exploradas 
sexualmente usadas como garantia de fertilidade para reproduzir e fazer crescer a comunidade escravizada. "O estupro, na verdade, era uma expressão ostensiva do domínio econômico do proprietário e do controle do feitor sobre as mulheres negras na condição de trabalhadoras." (DAVIS, 2016, n.p).

Ainda neste tempo, os estereótipos já existiam. Era comum encontrar na história e na literatura escravizada, casos sobre mulheres negras para só cuidar da casa de seu dono, já outra parte, a sua maioria, trabalhava na lavoura e no serviço braçal.

Nos EUA, durante a década de trinta do século XIX, as mulheres brancas começaram a se aliar às mulheres negras e aos movimentos feministas negros que pediam direitos iguais, valorização e ações antiescravagistas. No entanto, com a entrada da mulher no mercado de trabalho, a discrepância se tornou evidente entre as mulheres brancas e negras. Naquele período, existia muita dificuldade de uma mulher negra exescravizada conseguir um emprego e quando o conquistavam eram nas piores condições de trabalho e com os menores salários. As antigas escravizadas passaram a ser novas empregadas domésticas e a participação no espaço industrial só aumentou quando os Estados Unidos foram para a Segunda Guerra Mundial. A união entre o racismo e sexismo tornavam as mulheres negras um grupo menosprezado.

Os burgueses tratavam os negros como seres inferiores e por consequência eram afastados dos Direitos Civis, como o voto e a educação, pois, "de acordo com a ideologia dominante, a população negra era supostamente incapaz de progressos intelectuais" (DAVIS, 2016, n.p).

Neste contexto, percebe-se que existe uma hierarquia de gênero. Baseando-se na ideia de Simone de Beauvoir a qual "a mulher é o Outro por não ter reciprocidade do olhar do homem, para Grada Kilomba a mulher negra é o Outro do Outro, posição que a coloca num local de mais difícil reciprocidade.” (Apud RIBEIRO, 2019, n.p). É notório que o público negro feminino é um grupo com uma posição mais invisibilizada.

Essa hegemonia entre os povos está presente de formas diferentes e permanece em diversos setores da sociedade, bem como pode ser vista claramente na indústria dos videogames. No segundo Censo da Indústria Brasileira de Jogos Digitais feita pela empresa Homo Ludens divulgou que o número de mulheres na indústria de jogos digitais no Brasil triplicou nos últimos seis anos, porém, neste setor, ainda tem uma baixa 
diversidade de gênero e etnia, pois os dados mostram que apenas oito desenvolvedoras da indústria brasileira declaram ter sócias afrodescendentes.

\section{O DESIGN DE PERSONAGENS E A REPRESENTAÇÃO NEGRA FEMININA NOS JOGOS DIGITAIS}

De acordo com HOUAISS (1998), personagem deriva do latim dramatis persona, que significa figura do drama. A origem da criação de um personagem é proveniente da dramaturgia, uma das primeiras expressões artísticas da humanidade é "a arte de representar emoções por meio de personagens vivenciadas por atores" (COMPARATO, 2018, n.p).

As representações têm o poder de criação de arquétipos e modelos que são celebrados ou mesmo demonizados pela sociedade, tais imagens são efetuadas ao sabor do discurso vigente e manifestadas nestas construções, atribuindo heroísmo ou vilania á personas criadas dentro de ambientes e contextos que reforçam ou desconstroem ideais de grupos, povos, e nações, representando geralmente noções de hegemonia cultural.

Dessa forma, a potencialização destas narrativas e imagens dentro de um ambiente de diversão é elevada a um patamar poderoso. Este status pode ser conferido quando percebemos o poder de constituir conceitos que proliferam em rede, dentro da sociedade, erigindo percepções de verdades sobre comportamentos, relações, contextos históricos de atores sociais que podem constituir elementos de formação humana, política e social de um povo.

Assim, esse papel é constatado na ideação dos personagens dentro de contos e entretenimento, edificando arquétipos de um povo, tal fenômeno não é característica exclusiva da indústria do game, percebemos isso nas manifestações culturais como HQ, filmes e séries contemporâneas que contam com narrativas e discursos próprios, mas de penetração e ações menos interativa, qualitativa e quantitativamente menos poderosos que o game. Quando verificamos o mesmo fenômeno na cultura dos games, podemos constatar que a natureza e capilaridade dessas construções podem ter outros impactos.

A criação de personagens, também chamado de character design, teve sua evolução e história diretamente vinculadas à evolução tecnológica dos games, sua natureza e popularização. Como foi citado anteriormente, os jogos digitais eram feitos de 
modo simples devido aos limites da tecnologia envolvida em sua construção, portanto, estes, não tinham personagens, muito menos uma narrativa profunda.

De acordo com Rogers (2014), os primeiros jogos desenvolvidos eram renderizados em gráficos por vetores, as quais as imagens são construídas por linhas. $\mathrm{O}$ uso das cores apareceu após a implementação de gráficos rasterizados, com imagens produzidas a partir de pequenos pontos chamados pixels, que formam as linhas em um grid. Com o incremento exponencial das formas de representação gráfica, propiciados pelas capacidades dos hardwares e possibilidades dos softwares, foram possíveis personagens efetivos, com argumentos, história, perfis psicológicos, identidades, expressões, tudo que poderíamos atribuir a um ente vivente, com existência efetiva.

Conforme Sheldon (2004), o designer de personagens é o profissional que pensa nas características físicas, psicológicas e sociológicas dos personagens. O personagem principal, no caso o herói nos videogames, é que move a história e cria o conflito. Por meio dele, o jogador irá interagir no universo criado dentro do videogame. Segundo Rogers (2014), o personagem do jogador ou player character, PC, é definido como o personagem principal, que será controlado durante um game. Dependendo da história, ele irá enfrentar diferentes tipos de obstáculos com inimigos e bosses, também chamado de chefões, que podem ser humanos ou não.

Dentro do universo dos games, existe uma organização dos personagens, além dos personagens jogáveis, existem os companions e os não-jogáveis. Muito presente em jogos de FPS e MMO, os personagens companions é uma forma de pessoas jogarem juntas online, as quais cada uma escolhe seu personagem.

Além disso, constatamos também que os companions são controlados pela inteligência artificial do jogo, como por exemplo, na franquia de FPS de terror e sobrevivência Left 4 Dead da empresa Valve, como mostra a figura 2. Já os personagens não-jogáveis, popularmente conhecidos como NPCs ou non-player characters, estão presentes para auxiliar o personagem jogável durante a gameplay com informações, tarefas ou recompensas, ou seja, o jogador não o controla.

Figura 2: Left 4 Dead. 


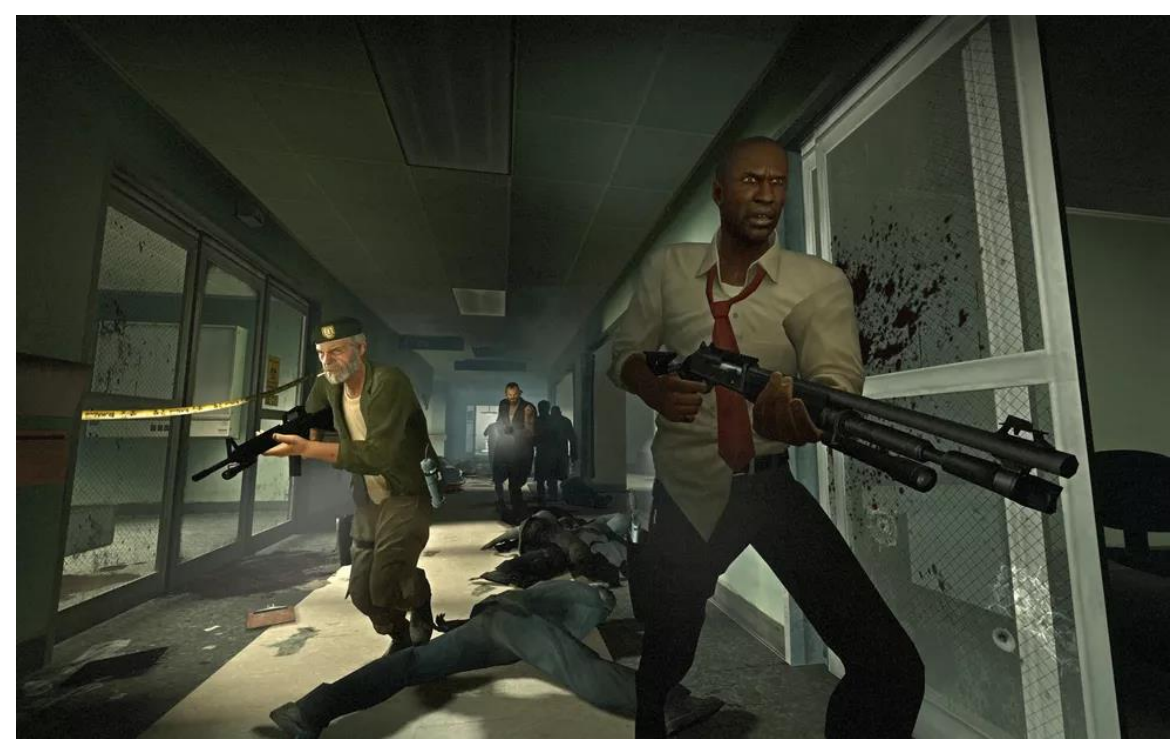

Fonte: https://store.steampowered.com/app/500/Left_4_Dead/

Posto isso, os primeiros personagens criados em jogos digitais eram baseados em cartoons, desenhos animados, e alguns deles se tornaram ícones da cultura pop, como o primeiro produzido para um jogo, o Pac-Man, publicado no ano de 1980.

Segundo Kent (2010), o Pac-Man é considerado como o videogame que fez mais sucesso na indústria americana dos arcades, cujo objetivo do jogo consiste em fazer o Pac Man, um círculo amarelo com uma boca, comer todos os pontos disponíveis no labirinto sem ser pego pelos quatro vilões, que são representados por fantasmas parecidos com esfregões. A Namco, empresa que desenvolveu o videogame, precisava produzir mais produtos, por consequência eles adicionaram mais elementos na história do Pac-Man.

Sendo assim, foi criada uma família, iniciando com a Ms. Pac Man, primeira personagem jogável feminina não humana em um jogo digital. Em relação às características deles, a diferença entre o Pac Man masculino para o feminino foi a adição de batom na boca e um laço vermelho. O jogo dela também recebeu novas cores voltadas para o público feminino. Tais modificações já traziam alguns indícios de como a questão de gênero seria tratada dentro do mundo do entretenimento virtual, assumindo e realçando vários arquétipos corriqueiros da sociedade.

Posteriormente, outros personagens que fizeram sucesso foram em Donkey Kong, desenvolvido por Shigeru Miyamoto em 1982, este jogo foi inspirado no filme King Kong de 1933 e da história de conto de fadas A Bela e a Fera, o qual tinha o próprio Donkey Kong, um gorila que pertence ao Jumpman. 
No referido game, o jogador comanda o Jumpman, cujo objetivo é resgatar a donzela Pauline do Donkey Kong passando por vários obstáculos no caminho. Posteriormente o Jumpman muda seu nome para Mario e o universo expande para uma franquia. Embora tenha a participação de uma personagem feminina, segundo Donovan (2010), a Pauline não participa de forma ativa, era essencialmente um objeto de afeto entre o Mario e Donkey Kong. Desde já percebemos uma característica do personagem feminino que está presente e amplamente difundida na sociedade como um todo, dos quais aparecem os elementos de fragilidade e indefensabilidade ligados ao perfil da mulher.

Neste período, além de Pauline, poucas personagens femininas foram criadas como protagonista no produto final e quando as criavam tinham dificuldade na representação, qualificação do personagem e sua conduta e imagem. Um dos casos mais notáveis de participação da mulher nos games foi Tomb Raider, uma franquia de aventura desenvolvida pela CORE Design Limited e publicada pela primeira vez em 1996 pela Eidos Interactive.

A protagonista é uma britânica, arqueóloga e caçadora de relíquias chamada Lara Croft. O videogame teve o intuito de fazer uma versão feminina de Indiana Jones, personagem masculino de uma série de filmes, com puzzles, enfrentamento de inimigos e uso de armas.

Sendo considerada a primeira representante feminina de sucesso no mercado de games, de acordo com a IGN (1996), a personagem Lara teve críticas negativas pelas feministas, devido aos estereótipos femininos, a suas características visuais hipersexualizadas, como a vestimenta justa e sumária favorecendo a exposição do seu corpo e a objetificação da mulher. "Essa mulher distante e sem poder é um arquétipo que se encaixa com perfeição no espaço tradicionalmente voltado para o mundo dos meninos" (SALEN; ZIMMERMAN, 2012, p. 42).

Devido às polêmicas apresentadas, a partir de cada atualização no jogo, as formas da personagem de Lara foram se modificando como é visto na figura 3. O jogo passou a focar mais na narrativa e com Lara mais jovem iniciando a suas aventuras como arqueóloga. Assim como houve mais aprofundamento em sua história, ocorreu também mudanças em sua indumentária e Lara ganhou uma nova visibilidade. 


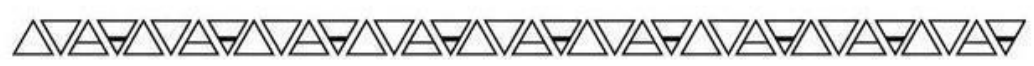

Figura 3: Versões dos modelos tridimensionais da Lara Croft ao longo do tempo.

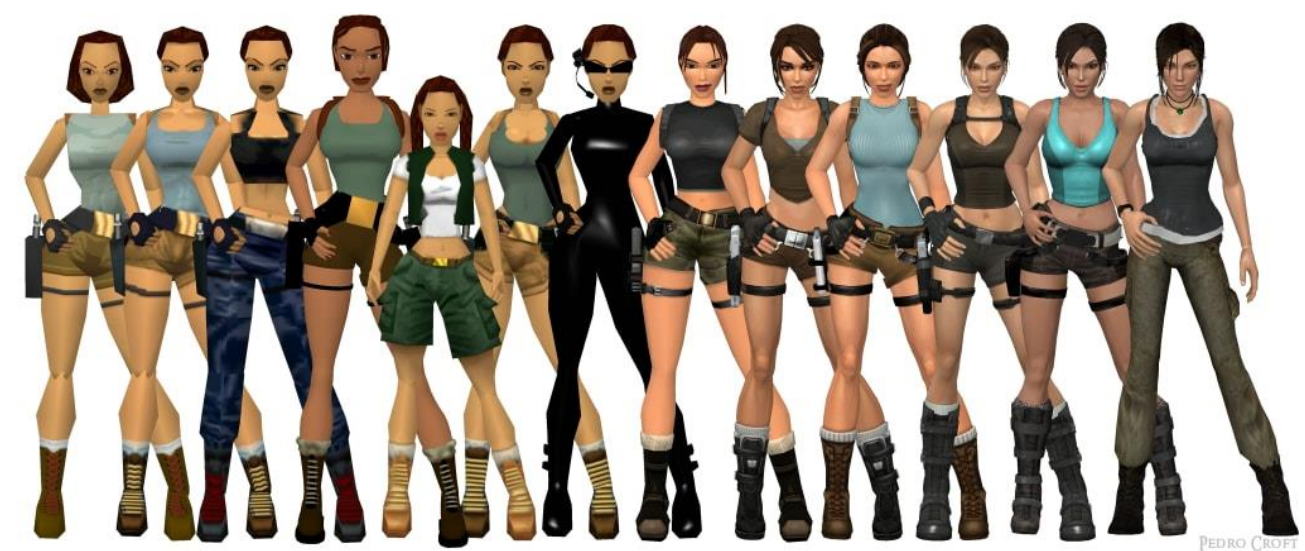

Fonte: https://vocal.media/gamers/tomb-raider-classic-vs-reboot

De acordo com Donovan (2010), a organização Children Now verificou os jogos mais vendidos em 2000 e revelou que as mulheres eram a minoria como personagens humanas jogáveis, participando apenas em 16\%. Glaubke, Miller, Mccrae e Espejo (2001) também identificaram frequentes estereótipos entre os personagens femininos e masculinos os quais, em algumas vezes, as mulheres eram representadas de forma hipersexualizada e os homens em uma figura extremamente musculosa. Dos jogos analisados existiam mais heróis brancos do que negros, "de 53 heróis, 46 eram brancos (87\%). Asiáticos/habitantes das Ilhas do Pacífico foram contabilizados em 8\%, afroamericanos apareceram em $4 \%$ e $2 \%$ dos heróis eram latinos. Não havia heróis ou salvadores americanos nativos". (GLAUBKE; MILLER; MCCRAE A.; ESPEJO, 2001, p. 22, tradução nossa).

Além disso, Donovan (2010) afirma sobre alguns videogames de origem japonesa que realizaram estereótipos com pessoas negras descrito como estilo blackface. Como mostra a figura 4, o jogo Square's Tom Sawyer tem como exemplo um personagem negro com lábios exageradamente grandes.

Alguns jogos japoneses caíram em estereótipos racistas de pessoas negras, em parte porque a composição racial mais homogênea do país significava que o racismo era raramente confrontado. Por exemplo, o role- playing game Square's Tom Sawyer de 1989, baseado - um tanto ironicamente - no romance de Mark Twain, As Aventuras de Tom Sawyer, retratou personagens negros como caricaturas no estilo "blackface" com lábios gigantes. (DONOVAN, 2010, n.p, tradução nossa.)

Figura 4: Blackface no jogo Square's Tom Sawyer. 


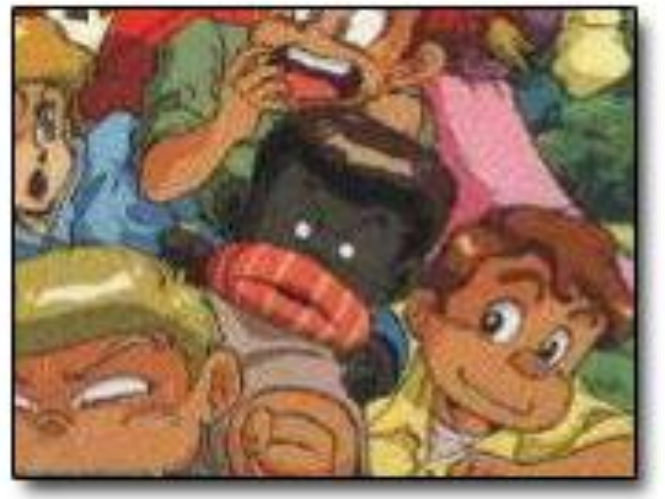

Fonte: https://www.cracked.com/article_16885_the-6-most-politically-incorrect-video-gamemoments.html

Dentro das organizações produtoras de videogames tais panoramas pareciam não ter repercussão alguma, eram tratados com normalidade e não foi possível encontrar representação mais contundente quanto a estes dados. Apesar de ser detectado com clareza, o racismo era tratado de forma sigilosa nas empresas do ocidente. As situações aconteciam, mas não eram tratados de forma aberta, como por exemplo, "alguns editores de jogos pressionando os designers para "branquear" o tom de pele dos personagens negros ou removê-los totalmente", além de excluir outras etnias como os asiáticos, com o receio de não vender o produto (DONOVAN, 2010, n.p, tradução nossa).

Com base nas pesquisas realizadas para este artigo, pode-se considerar que a personagem D'arci Stern de Urban Chaos, presente na figura 5, foi a primeira personagem jogável negra como uma protagonista. Com o gênero FPS, foi lançado primeiramente no Windows em 1999 e depois para Playstation 2 e Dreamcast. Segundo o site IGN (1999), D'arci era policial, tinha habilidades de luta e enfrentava as gangues da cidade. Publicado pela Eidos Interactive e desenvolvido pela Mucky Foot por Mike Diskett, Fin McGechie e Guy Simmons, o videogame é similar a Tomb Raider. No entanto, tinha uma característica inovadora para a época em que foi feito com a inserção de um mundo aberto. Dessa forma, dava mais possibilidades de ordem na gameplay com chances de explorar espaços e elementos no ambiente.

Figura 5: Heroína D’arci Stern. 


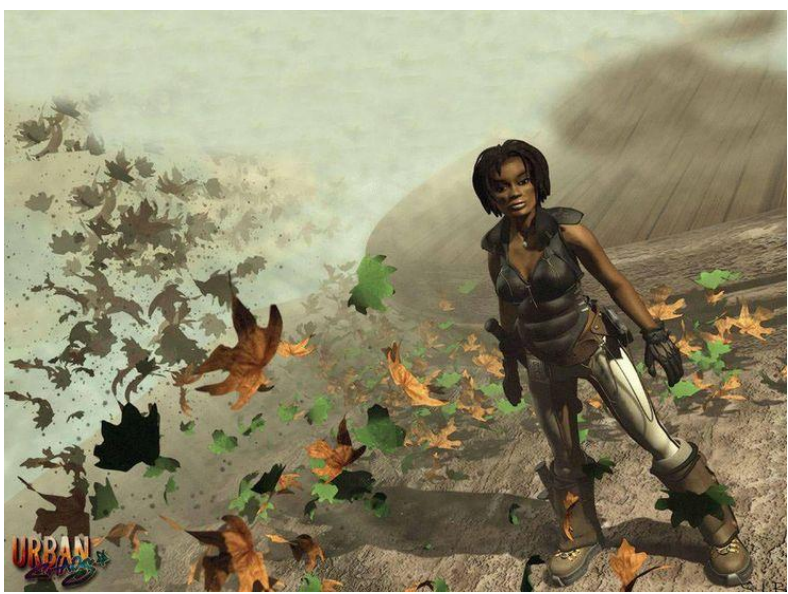

Fonte: https://blerds.atlantablackstar.com/2015/06/16/14-of-the-best-playable-black-femalecharacters-in-video-games/

Das documentações e estudos feitos até agora, a dificuldade em aparecer personagens femininas negras jogáveis e até mesmo como heroína em um jogo digital persiste. Isso impõe a nós pesquisadores investigar as prováveis causas e as motivações que levam a essa problemática. A situação vai além das personagens nos jogos eletrônicos e pode ser vista em uma perspectiva estrutural desta indústria. Com isso, é possível identificar fatores como os sociais, o de produção, o mercadológico e o científico.

Assim, pode-se perceber que as representações de personagens femininas negras na cultura de massa refletem o social, dessa forma, com o avanço tecnológico, há uma difusão no mundo dessa concepção pelo meio digital.

As realizações acadêmicas e livros com a temática sobre identidade étnica-racial e gênero em jogos eletrônicos não aparecem juntos frequentemente, mesmo tendo seu valor de importância. Isso possivelmente se deve ao fato do conceito de eurocentrismo comentado por Coronil (1996) de prevalecer uma cultura europeia e anglofônica concentrando todo o poder e estudos neste grupo. Definido o espaço entre colonizador e colonizado, os povos africanos, indígenas e asiáticos passaram a ser subalternos. Além disso, a escrita em si é uma forma de expressão que colabora com o registro de voz das mulheres negras, que são silenciadas em diversas áreas.

A escrita transforma-se, então, em espaço seguro de onde é possível desafiar as imagens negativas e estereotipadas e externamente definidas sobre mulheres negras, produzindo outras imagens e representações sociais femininas negras positivadas, restituindo-lhes politicamente sua condição de sujeito histórico.

(CARDOSO, 2018). 
Nesta perspectiva podemos perceber que a escrita pode reavaliar o discurso imagético sem, no entanto, eliminá-lo, as palavras sinalizam conceitos e valores que o desenvolvimento e imbricamento das imagens e contexto de funcionamento declaram ostensivamente.

\section{PÚBLICO NEGRO FEMININO GAMER}

No início, entre a década de 1970 e 1990, os videogames eram normalmente tratados como produtos feitos de "meninos para meninos" com o motivo de que o público feminino não se interessasse e, portanto, não seria muito vantajoso para vender. A maioria dos games online voltados para meninas eram temas como "moda, beleza, coisas relacionadas à casa, ou que devem ser jogos simples e de fácil aprendizado como os jogos casuais" (Souza; Camurugy; Alves, 2009, p. 44). Enquanto os jogos para os meninos eram mais ligados à aventura, ação e luta.

Segundo Aliaga na IGN Brasil, dados da Pesquisa Game Brasil 2020 (PGB) traçaram o perfil gamer brasileiro e constatou que o público feminino continua maior que o masculino com $69,8 \%$, independente do tipo de plataforma em que jogam. O público feminino gamer tem aumentado ano após ano e superado a estatística masculina desde 2016, mas as pesquisas não mostram dados aprofundados de cunho étnico-racial. A pesquisa também aponta uma falta de aceitação em ser uma mulher gamer. Entretanto, mesmo existindo um público em potencial, mulheres em sua maioria não se consideram como gamers independente de ser casual gamer ou hardcore gamer. Partindo pelo conceito de que o gênero feminino no geral é desprezado, é possível que a mulher negra tenha mais dificuldades em se sentir pertencente na comunidade gamer.

O racismo e a questão da representatividade negra na sociedade são um assunto que está em momento de ascendência mais uma vez, devido a acontecimentos sucessivos que ocorreram principalmente em 2020 e geraram movimentos tanto nas ruas como em redes sociais. O movimento Black Lives Matters cresceu mundialmente em consequência ao caso ocorrido com o assassinato do estadunidense George Floyd pelo policial branco Derek Chauvin. Conforme Queiroga na ESPN, George era um homem negro que foi sufocado com um dos joelhos do policial durante a abordagem. 
Esse e outros casos começaram a surgir com mais frequência e afetam a indústria dos videogames. Existem grandes empresas que adicionam personagens ou conteúdo inclusivo e estão sendo atacadas pelo aumento de uma comunidade tóxica de jogadores que não aceitam e excluem a minoria, seja no conteúdo do game quanto os próprios jogadores.

Embora todas as questões apresentadas, é visível notar que o racismo estrutural também afeta as classes sociais, e isso influencia no que diz respeito à acessibilidade aos dispositivos digitais, meio que é essencial para jogar videogames. Além disso, segundo o PGB 2020, o celular ainda é o principal meio para usar internet no Brasil e também o mais utilizado para jogar. De acordo com dados da PNAD Contínua TIC 2018, o país ainda tem lugares onde não tem serviço de internet. "Uma em cada quatro pessoas no Brasil não tem acesso à internet. Em números totais, isso representa cerca de 46 milhões de brasileiros que não acessam a rede."(TOKARNIA, 2020).

No estudo sobre desigualdade racial da pobreza no país feito pelo Ipea, resultados mostram que a chance de negros serem pobres ainda era 2,1 vezes maior que a dos brancos em 2014. A condição de baixa renda restringe a população negra em ter tecnologias atuais como computador e consoles de mesa.

Apesar das adversidades, o público feminino negro gamer existente precisa do seu lugar de fala. Por esses ideais, vem surgindo perfis de influência digital de mulheres negras que jogam e passam uma nova perspectiva para a comunidade gamer no geral.

\section{CONSIDERAÇÕES FINAIS}

Foi percebido que o desenvolvimento de jogos como uma mídia digital favorece a exposição de situações culturais e ideológicas enraizadas na sociedade e mostra-se possível a mudanças de acordo com o tempo. É cabível a responsabilidade de empresas e desenvolvedoras impulsionarem mais inclusão social na indústria, diversificando e valorizando públicos já existentes e em potencial, porém até então lidados como secundários ou inexistentes.

Assim como acontece com o designer de personagens com a tarefa da criação do herói no videogame, que carrega um espaço de mensagem significativo e influencia a experiência dos usuários. Como numa relação de troca, as produtoras de videogames que 
focam em seus diversos públicos, podem influenciar o modo de pensar dos consumidores. Assim como os consumidores podem se reconhecer em seu espaço e reivindicar sua presença e seu poder de pertencimento para ter mudanças no cenário.

Podemos concluir que o protagonismo negro feminino continua sendo minimizado dentro da indústria de games, é multifatorial e segue uma lógica do pensamento colonial ocidental, constituídos por fatores extrínsecos a indústria, como também intrínsecos. Os fatores verificados apenas reafirmam o atual sistema patriarcal eurocêntrico e colonial, o qual o sistema econômico capitalista ainda exclui o que não é padrão. Estes até então têm o receio de mudança devido ao costume de agradar aos consumidores brancos e homens que não aceitam a diversidade em seu meio.

Existe uma urgência de um pensamento com base no feminismo negro, como aponta Ribeiro (2019), para se pensar outras possibilidades para as plataformas eletrônicas de entretenimento e entender como o mercado e os consumidores se comportam para produzir um produto mais coerente e inclusivo. Assim como Djamila Ribeiro (2019) define, todos têm lugar de fala. Precisa o negro ocupar o seu lugar de representatividade no game. O videogame como produto atualmente valorizado e rentável no mercado pode ser responsável por mudanças sociais e econômicas no mundo inteiro. Por isso, é importante que temas como o protagonismo negro feminino serem abordados constantemente nas demais mídias, especialmente na tão ascendente indústria lucrativa de jogos digitais. Para serem lembrados e investigados de modo frequente com o objetivo de não ser subjugado a uma incógnita.

\section{REFERÊNCIAS BIBLIOGRÁFICAS}

ALIAGA, Víctor. 69,8\% das mulheres no Brasil jogam jogos eletrônicos, indica pesquisa. IGN Brasil, 2020. Disponível em: <https://br.ign.com/brasil/82696/news/698-das-mulheres-no-brasiljogam-jogos-eletronicos-indica-pesquisa $>$. Acesso em: 28 ago. 2020.

BUCHANAN, Richard. Design Research and the New Learning. Design Issues, Massachusetts Institute of Technology, v. 17, n. 4, p. 3-23, 2001. Disponível em: 〈https://doi.org/10.1162/07479360152681056> . Acesso em: 22 out. 2020.

CARDOSO, Claudia Pons. EXPERIÊNCIAS DE MULHERES NEGRAS E O FEMINISMO NEGRO NO BRASIL. Revista da Associação Brasileira de Pesquisadores/as Negros/as (ABPN), [S.1.], v. 10, n. 25, p. 317-328, jun. 2018. ISSN 2177-2770. Disponível em: <https://abpnrevista.org.br/index.php/site/article/view/618>. Acesso em: 23 fev. 2021.

COMPARATO, Doc. Da Criação ao Roteiro: teoria e prática. 5. ed. São Paulo: Summus Editorial, 2018. E-book. 
CORONIL, Fernando. Beyond occidentalism? Towards non-imperial geohistorical categories. Cultural Anthropology, v. 11, n. 1, p. 51-87, Feb. 1996.

DAVIS, Angela. Mulheres, raça e classe. 1. ed. São Paulo: Boitempo, 2016. E-book.

DONOVAN, Tristan. Replay: The History of Video Games. Yellow Ant, 2010. E-book.

GLAUBKE, Christina R.; MILLER, Patti; MCCRAE A., Parker; ESPEJO, Eileen. Fair Play?: Violence, Gender and Race in Video Games. Children Now, Oakland, CA, 2001. Disponível em: <https://files.eric.ed.gov/fulltext/ED463092.pdf> Acesso em: 17 ago. 2020.

KENT, Steven L. The Ultimate History of Video Games: from Pong to Pokemon and beyond the story behind the craze that touched our lives and changed the world. 1. ed. Three Rivers Press, 2010. E-book.

KOOGAN, Abrahão; HOUAISS, Antônio. Koogan/Houaiss: Enciclopédia e Dicionário Ilustrado. 3. ed. Rio de Janeiro: Seifer, 1998.

OSORIO, Guerreiro Rafael. TD 2487 - A Desigualdade Racial da Pobreza no Brasil. IPEA, 2019. Disponível em: $\langle$ https://www.ipea.gov.br/portal/index.php?option=com_content $\& v i e w=\operatorname{article} \& i d=34915>$ Acesso em: 21 set. 2020.

Painel Gratuito 2020. 7. ed. PGB, 2020. Disponível em: <https://www.pesquisagamebrasil.com.br/pt/ebooks/>Acesso em: 21 set. 2020. Ebook.

QUEIROGA, Luis. Rematch: A realidade do brasileiro afasta negros do cenário de esportes. ESPN, 2020. Disponível em: <https://www.espn.com.br/esports/artigo//id/7030954/rematch-arealidade-do-brasileiro-afasta-negros-do-cenario-de-esports> Acesso em: 21 set. 2020.

RIBEIRO, Djamila. Lugar de Fala: (Feminismos Plurais). Pólen Livros, 2019. E-book.

ROGERS, Scott. Level Up!: The Guide to Great Video Game Design. Wiley, 2014. E-book.

SAKUDA. L. O.; FORTIM, I. (Org.). 2o Censo da Indústria Brasileira de Jogos Digitais. Ministério da Cultura: Brasília, 2018.

SALEN, Katie; ZIMMERMAN, Eric. Regras do Jogo: Fundamentos do Design de Jogos (Volume 4). 1. ed. Blucher, 2012.

SHELDON, Lee. Character Development and Storytelling for Games. 1. ed. Boston, MA: Thomson Course Technology PTR, 2004.

SCHELL, Jesse. The Art of Game Design: A Book of Lenses. 1. ed. Burlington, MA, USA: Morgan Kaufmann Publishers, 2008.

SOUZA, Alessandra de; CAMURUGY, Laiza; ALVES, Lynn. Games e gênero: a emergência dos personagens femininos. Salvador: Uneb, 2009. 5 p. Disponível em: $\langle$ http://www.sbgames.org/papers/sbgames09/culture/short/cults10_09.pdf $\rangle$. Acesso em $28 \mathrm{de}$ junho de 2020. 
TOKARNIA, Mariana. Celular é o principal meio de acesso à internet no país. O acesso pelo celular aumentou para 98,1\% de 2017 para 2018. Rio de Janeiro: Agência Brasil, 2020. Disponível em: <https://agenciabrasil.ebc.com.br/economia/noticia/2020-04/celular-e-oprincipal-meio-de-acesso-internet-no-pais $>$ Acesso em: 21 set. 2020.

Tomb Raider: PlayStation finally has its own Mario. IGN Brasil, 14 dez. 1996. Disponível em: <https://www.ign.com/articles/1996/12/14/tomb-raider-5> . Acesso em: 8 nov. 2020.

Urban Chaos: It's the end of the world as we know it, and I feel like it's time to open up a can of whoop-ass. IGN Brasil, 6 de maio de 1999. Disponível em: <https://www.ign.com/articles/1999/05/07/urban-chaos-6> Acesso em: 8 nov. 2020.

Urban Chaos Demo: Take to the dirty streets in Mucky Foot's high-impact action title. IGN Brasil, 19 nov. 1999. Disponível em: 〈https://www.ign.com/articles/1999/11/20/urban-chaos-demo> Acesso em: 8 nov. 2020.

Recebido em: 08/02/2021

Aprovado em: 16/10/2021 